\title{
Performance Analysis of AODV, DSDV AND ZRP ROUTING PROTOCOLS FOR WIRELESS SENSOR NETWORKS USING NS2 TOOL
}

\author{
Faïza Tabbana \\ Assistant Professor, Department of Telecommunication Engineering, Military \\ Academy, Fondek Jedid, Tunisia
}

\begin{abstract}
This paper presents a literature review on WSN networks, in which the capacity of network nodes is limited with respect to energy supply, restricted computational capacity and communication bandwidth. WSN is a complex set of applications, link technologies, communication protocols, traffic flows and routing algorithms. Simulation is a predominant technique used to study and analyze the performance of a wireless senor network design. To prolong the lifetime of these sensor nodes, designing efficient routing protocols are critical. Basically, the Routing protocols for wireless sensor networks are responsible for maintaining the routes in the network which ensures reliable multi-hop communication. To address this issue, in this paper, various protocols like AODV (Ad-hoc on-demand distance vector routing), DSDV (Destination-Sequenced Distance-Vector Routing) and ZRP (Zone Routing Protocol) are discussed along with various comparative parameters like Throughput, Packet Loss Ratio, End to End Delay and Dropped Packets. The performance of these protocols varies depending on the simulation environment. It will be analyzed in two ways. Firstly, by varying nodes within a margin of 10 to 100 nodes. Another way is by keeping the number of nodes constant and varying the speed of nodes from $10 \mathrm{~m} / \mathrm{s}$ to $90 \mathrm{~m} / \mathrm{s}$.
\end{abstract}

\section{KEYWORDS}

Wireless Sensor Network, AODV, DSDV, ZRP and Performance Metrics.

\section{INTRODUCTION}

Wireless sensor network, is one of the most considered factors in this era. A Wireless sensor network (WSN) is a collection of homogenous, self-organized nodes called sensor nodes. Sensor nodes are densely deployed either within the sink or very close to it and have restricted power, computational capacity and memory [20]. Sensor nodes are connected to wireless radio frequency link. A WSN is a network composed of mobile nodes mainly characterized by the absence of any centralized coordination or fixed infrastructure, which makes any node in the network acts as a potential router [20]. WSN are also characterized by a dynamic, random and rapidly changing topology [2]. The basic task of sensor networks, is to sense the events, collect data and then send it to their requested destination. Civilian application domain of wireless sensor networks has been considered later on, such as environmental, healthcare and production, smart home etc. Their applications range from simple wireless low data rate transmitting sensors to high data rate real time systems like those used for monitoring large retail outlets [1]. All nodes of these networks behave as routers and take part in discovery and maintenance of routes to other nodes in the

David C. Wyld et al. (Eds): ITCSE, NLCA, ICAIT, CAIML, ICDIPV, CRYPIS, WiMo - 2020

pp. 279-297, 2020. CS \& IT - CSCP 2020

DOI: $10.5121 /$ csit.2020.100525 
network [20]. An Ad-Hoc routing protocol must be able to decide the best path between the nodes, minimize the bandwidth overhead to enable proper routing, minimize the time required to converge after the topology changes [26]. The primary goal of this paper is to evaluate performances of AODV, DSDV and ZRP protocols for different scenarios of variable density of nodes and mobility using NS-2 network simulator. The performance metrics consist of varying number of nodes and network dynamicity in terms of node evaluated speed. This paper is organized as follow: section 2 begins with a description of AODV, DSDV and ZRP protocols. Section 3 presents the methodology and procedures of our current study. Section 4 discusses the simulation environment. Section 5 describes the parameters used to analysis running programs with NS-2 tool. Finally, we evaluate and compare the performance of AODV, DSDV and ZRP protocols. The paper concludes with future works directions in section 7 .

\section{Routing Protocols}

Routing in WSN is a challenging task due to highly dynamic environment [26]. There are different categories of routing protocols in wireless sensor networks such as proactive, reactive and hybrid routing protocols [3]. They differ from each other on the way they obtain the routing information.

\subsection{Proactive routing protocols}

Table Driven Protocols can be named as proactive protocols [22, 23, 25]. Table driven ad hoc routing protocols maintain at all times routing information regarding the connectivity of every node to all other nodes that participate in the network. Also known as proactive, these protocols allow every node to have a clear and consistent view of the network topology by propagating periodic updates $[14,10,18]$. In proactive routing, fresh list of destination and their routes are maintained by periodically distributing routing tables through the network. This type of protocols adds a new attribute, sequence number to each route table entry at each node. The routing information computed and shared and the path is set prior to the actual transfer of data packets between the source and the destination [7, 4]. This category of protocols has large bandwidth and more memory requirements making them more suitable for wired networks only [8]. Examples of proactive routing protocols are Destination Sequence Distance Vector (DSDV), Optimized Link State Routing Protocol (OLSR), Fisheye State Routing (FSR), and Source- Tree Adaptive Routing protocol (STAR) $[8,11,12]$. The selected protocol in this study is DSDV.

\subsection{Reactive routing protocols}

This type of routing protocols creates a route between the source and destination node only when the source node requires a route to the destination node [32]. It is a reactive or on demand routing protocol. When a node requires a route to a destination, it initiates a route discovery process within the network. This process is completed once a route is found or all possible route permutations have been examined [11]. Examples of reactive routing protocols are, Dynamic State Routing protocol (DSR), Ad hoc On-Demand Distance Vector Routing protocol (AODV), Ad-hoc on Demand Multipath Distance Vector (AOMDV), associativity-based routing (ABR) and Location-Aided Routing (LAR) [8, 6, 12]. The protocol considered here is AODV.

\subsection{Hybrid routing protocols}

These protocols combine characteristics of proactive and reactive protocols and are mostly used for hierarchal routing [22, 23]. In this protocol intermediate nodes have information about network and its closest node. Zone radius is used to define the zone size that is defined by number of hops $[14,10,16,17,19,25]$. Hybrid routing protocols cartels the advantages of proactive as 
well as reactive routing protocols and at the same time hybrid routing protocols overcome disadvantages of proactive and reactive routing protocols [23]. The limitation of these protocols is that nodes consume more memory and power as they have to maintain high-level topological information. Some examples of these protocols are Zone Routing Protocol (ZRP) and ZHLS (Zone Based Hierarchical Link State Routing Protocol) [25]. Figure 1, illustrates different classes of ad-hoc routing protocols.

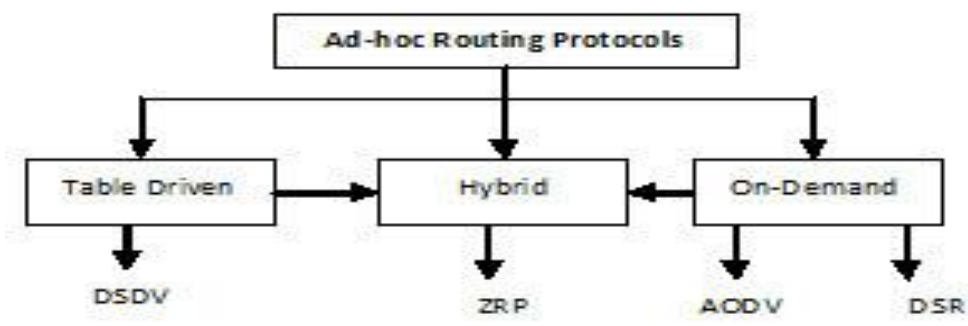

Figure 1. Classification of Routing Protocols

\section{ImPlantation OF Different Routing Protocols USED IN ANALYSIS}

\subsection{Destination Sequenced Distance Vector (DSDV)}

DSDV [2] is a table-driven algorithm based on the classical Bellman-Ford routing mechanism, but guaranteeing loop-freedom via sequence numbers [1, 7, 19,21]. Every mobile node in the network maintains a routing table in which all of possible destination within the network and the number of hops to each destination are recorded. Each entry is marked with a sequence number assigned by the destination node. The sequence numbers enable the mobile nodes to distinguish stale routes from newer ones, avoiding the formation of routing loops. Two different updates are defined: the first is known as a full dump, it carries all available routing information of the node and, attending to the size of the network, it can require multiple network protocol data units (NPDUs) [12, 24]. It is sent periodically. The second kind of update packets are named incremental and they are sent by a node when it detects a decisive change in the network. Update messages contain the address of the destination, the number of hops to reach the destination and the sequence number of the advertised route. Routes labelled with the most recent sequence number are always preferred. In the event that two updates have the same sequence number, the route with the smaller metric is used. Routes availability to all destinations implies that much less delay is involved in route setup process. The data broadcast by each node will contain its new sequence number, the destination's address, the number of hops count [24].

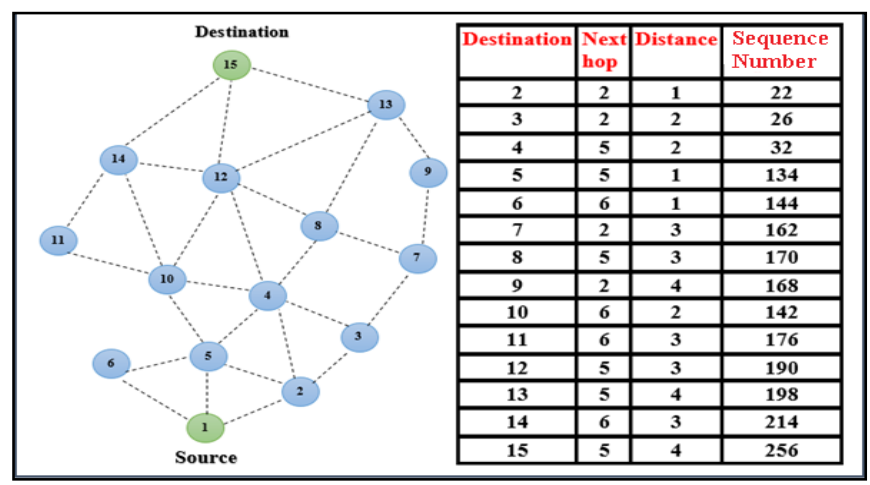

Figure 2. DSDV routing table for above nodes 


\section{Implementation Decision}

The absence of a standard makes some parameters of the algorithm be without clear definition $[29,20]$. The constants and parameters which were used in the implementation of the algorithm are shown in Table 1.

Table 1. Constants used in DSDV simulation [29]

\begin{tabular}{|l|l|}
\hline Periodic route update interval & $1 \mathrm{~s}$ \\
\hline Time without news to declare a link broken & $3 \mathrm{~s}$ \\
\hline $\begin{array}{l}\text { Time after the link break to remove the entry } \\
\text { from the routing table }\end{array}$ & $4 \mathrm{~s}$ \\
\hline Size of control packets & $\begin{array}{l}\text { Full dump }->4096 \text { bits incremental-> 512 } \\
\text { bits }\end{array}$ \\
\hline $\begin{array}{l}\text { Maximal number of entries fitting in a full } \\
\text { dump packet }\end{array}$ & 32 entries \\
\hline
\end{tabular}

\subsection{AODV}

The Ad hoc On Demand Distance Vector (AODV) routing algorithm is a routing protocol designed for ad hoc mobile networks [20]. AODV is capable of both unicast and multicast routing [20]. It is an on-demand algorithm, meaning that it builds routes between nodes only as desired by source nodes. It maintains these routes as long as they are needed by the source. Ad hoc On-demand Distance Vector routing (AODV) protocol enables dynamic, self-starting, multihop routing between mobile nodes to establish the ad hoc network [1, 2, 3]. The mobile nodes obtain routes only for those destinations that are in the active communication. Link breakages are detected by the affected set of nodes and they invalidate the routes using the lost link [1,7]. When a source node desires to establish a communication session, it initiates a path-discovery process to locate the other node [28]. AODV builds routes using route requested and route reply mechanisms [20]. In order to discover the path, a route request (RREQ) packet is broadcasted across the network to find the route to the destination. Nodes receiving this packet update their information for the source node and set up backwards pointers to the source node in the route tables. To find a path to the destination, the source a initiates Route Request (RREQ) packet across the network and it contains the source address, destination address, source sequence number, destination sequence number, the broadcast identifier and the time to live field [32]. Nodes keep track of the RREQ's source IP address and broadcast ID [20]. If they receive a RREQ which they have already processed, they discard the RREQ and do not forward it [20]. When a node forwards a RREQ packet to its neighbours, it also records in its routing table the node from which the first copy came and it is required by the node to construct the reverse path for the RREP packet. AODV uses only symmetric links because the route reply packet follows the reverse path of route request packet. Information about the preceding node from which the packet was received is recorded when a node receives a RREP packet, in turn to forward the data packets to this next node as the next hop toward the destination. Once the source node receives a RREP it can begin using the route to send data packets [32, 15]. Hello messages are broadcasted periodically among the nodes in order to detect link break and if the intermediate nodes moves or changes then this information send to its upstream neighbours and so on till it reaches the source upon which the source can reinitiate route discovery if required [32, 16, 17, 19]. Figure 3 shows the propagation of the RREQ across the network. 


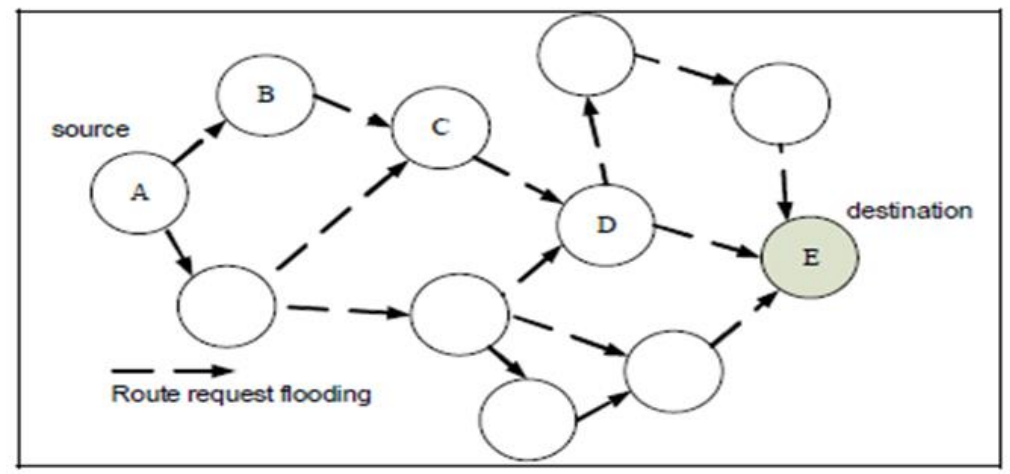

Figure 3. Route Request flooding

Once the RREQ reaches the destination or an intermediate node with a fresh enough route, this node responds by unicasting a route reply (RREP) packet back to the neighbour from which it received the RREQ packet. The path which follows the RREP message is shown in Figure 4.

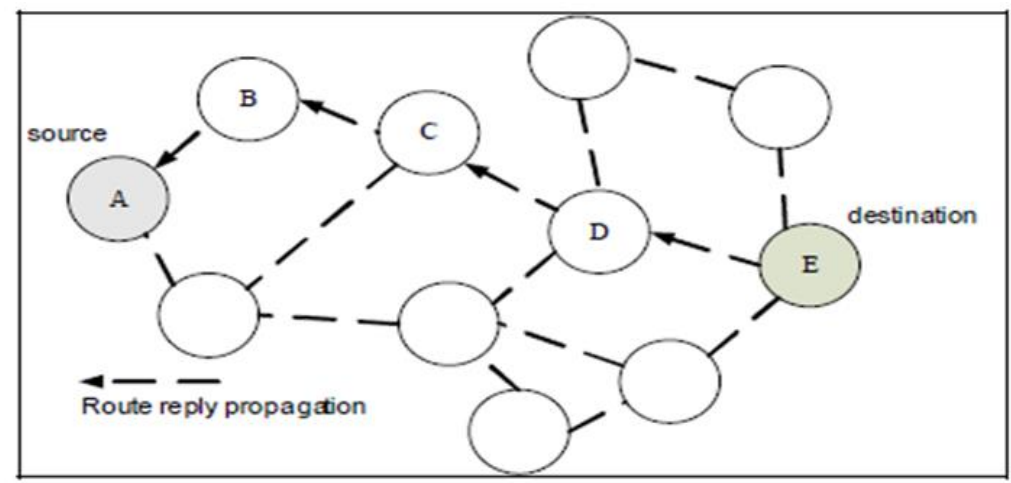

Figure 4. Route Reply propagation

As long as the route remains active, it will continue to be maintained. A route is considered active as long as there are data packets periodically traveling from the source to the destination along that path. Once the source stops sending data packets, the links will time out and eventually be deleted from the intermediate node routing tables. If a link break occurs while the route is active, the node upstream of the break propagates a route error (RERR) message to the source node to inform it of the now unreachable destination(s). After receiving the RERR, if the source node still desires the route, it can reinitiate route discovery process [20].

\section{Implementation Decision [29]}

Table 2. Constants used in AODV simulation

\begin{tabular}{|l|c|}
\hline Hello interval & 1 second \\
\hline Time without news to declare a link broken & 3 seconds \\
\hline $\begin{array}{l}\text { Time after link break declaration to remove the } \\
\text { entry from the table }\end{array}$ & 4 seconds \\
\hline RREQ sent without replay arrival at time & 3 \\
\hline Times a RREP is resent without ACK arrival & 2 \\
\hline
\end{tabular}




\subsection{Zone Routing Protocol (ZRP)}

ZRP is designed and presented by "Zygmunt Haas" of Cornell University, New York USA Zone [4]. This protocol is a correlation of proactive and reactive routing protocols (i.e.it is both table driven and demand driven) [26]. The hybrid approach can be more efficient than traditional routing. ZRP produces much less routing traffic than a pure reactive or proactive protocol. These protocols are designed to increase scalability by allowing nodes with close proximity to work together as a zone or cluster [1]. A node keeps routes to all the destinations in the routing zone. In this, a network is divided into zones. ZRP has three sub-protocols which are Intra zone Routing Protocol (IARP), Inter zone Routing Protocol (IERP) and Border cast Resolution Protocol (BRP) $[26,31]$. Intra zone Routing Protocol is used when route lies within the zone and Inter zone Routing Protocol (IERP) is used outside the zone. Figure 4 illustrates the operation of the ZRP protocol. We deduce that if the destination is not inside the zone, then the source broadcasts Route Request message to the peripheral nodes.

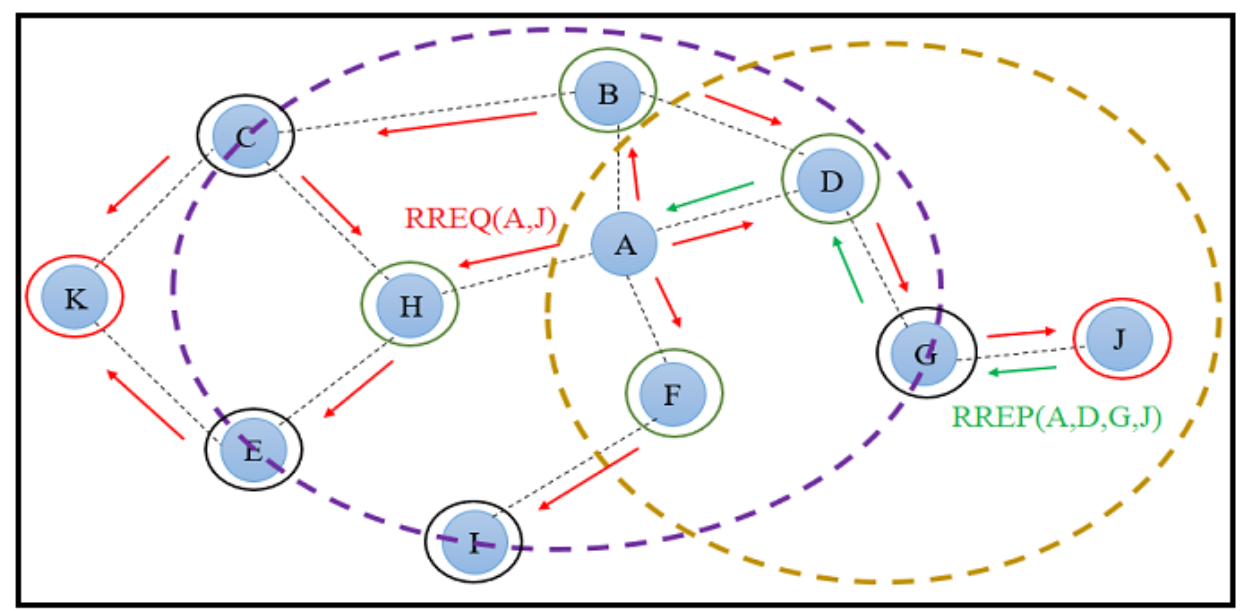

Figure 5. ZRP Routing Protocol Transmission

\section{Problem Statement}

The goal of this work is to compare and analyse the performance of three routing protocols based on demand behaviour i.e. on-demand Distance Vector (AODV), Destination Sequence Distance vector (DSDV) and ZRP protocols for wireless ad-hoc networks. Comparison has been made based on performance metrics like Throughput, packet delivery ratio (PDR), end to end delay and data packet loss with respect to different scenarios one by varying the density of nodes and finally by varying the mobility of nodes. The general objectives can be outlined as follows:

- Study of wireless networks

- Detailed study of AODV, DSDV and ZRP protocols

- Generate a simulation environment that could be used for simulating protocols

- Simulate the routing protocols on the basis of different scenarios by varying number of nodes and speed of nodes.

- Discuss and compare the result of the proposed work and concluding by providing the best routing protocol. Comparison of routing protocol is one in different network simulators, but not in ns 3 [30]. 
Figure 7 shows a scenario with a topology of 100 nodes. Node 0 is the source which transmits data. Node 100 is the sink or the destination for the whole network.

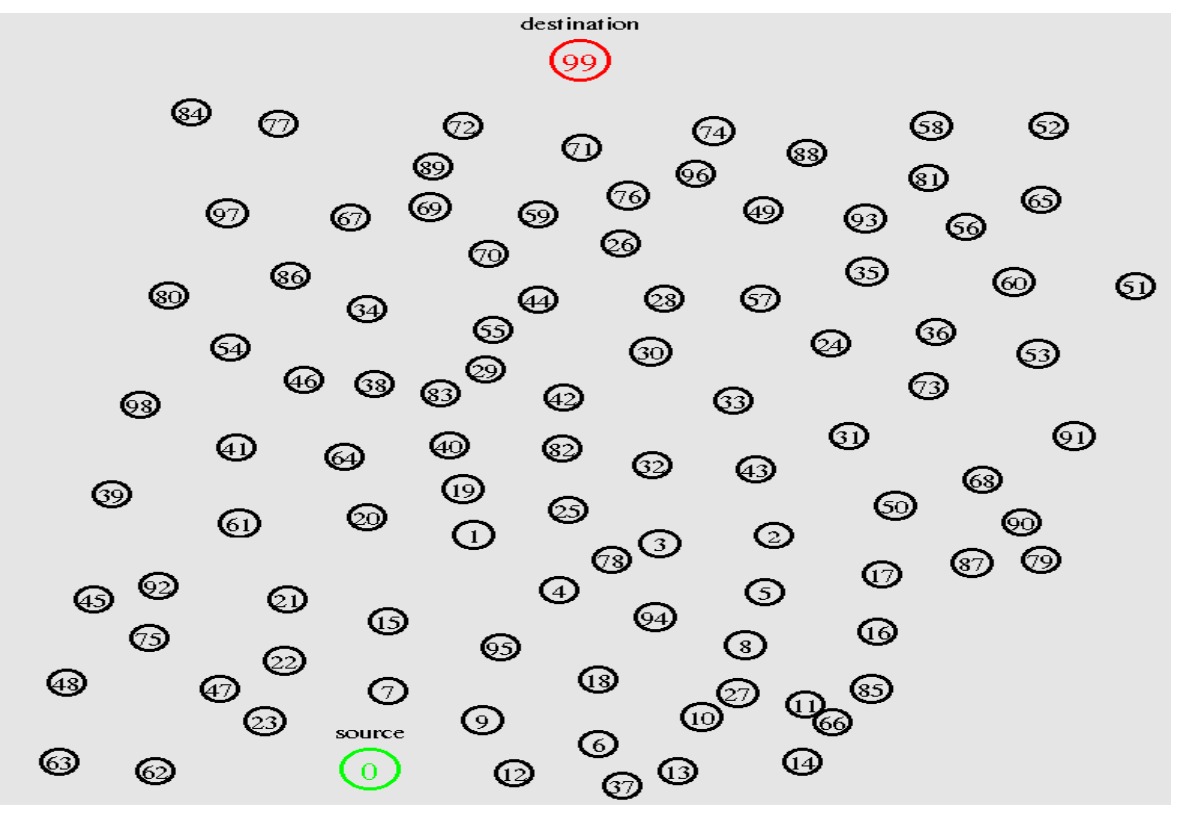

Figure 6. A WSN Topology with 100 nodes used in simulation

\section{Performance Metrics}

Various Quality of Service parameters used for analysis routing protocols are defined as follows.

\subsection{Packet Delivery Ratio (PDR)}

It is the ratio of deliver packet which is send by the source node and received by the destination node. When packet delivery ratio is high then performance is better [5, 30]. Mathematically, it can be written as in this equation:

$$
P D R=\frac{\sum_{i=1}^{N} \text { Total packets received by all node destination }}{\sum_{i=1}^{N} \text { Total packets send by all source }}
$$

PDR is calculated in \% (percentage). Higher values of PDR carry better performance.

\subsection{Average throughput}

It is the ratio between the actual number of packets transmitted by the nodes in the system to the number of successfully delivered packets at the base station [30]. The throughput is usually measured in bits per second (bit/sec), and sometimes in data packets per second or data packets per time slot. Higher throughput is always desirable in a communication system [30, 26]. The average throughput is given as follows:

$$
\text { Average Throughput }=\frac{\text { recdvSize }}{\text { stopTime-startTime }} *\left(\frac{8}{1024}\right)
$$




$\begin{array}{lll}\text { Where: } & & \\ \text { recdSize } & = & \text { Store received packet 's size } \\ \text { Stop Time } & = & \text { Simulation stop time } \\ \text { startTime } & = & \text { Simulation start time }\end{array}$

\subsection{End to End delay}

End-to-end delay refers to the time taken for a packet to be transmitted across a network from source to destination. A data packet may take longer time to reach to the destination due to queuing and different routing paths [26]. It is derived in ms (mille second). Smaller values of End-to-end delay carries improved performance. The End-to-end delay is described as:

$$
\mathrm{EED}=\frac{\sum_{\mathrm{i}=1}^{\mathrm{n}}(\mathrm{Tri}-\mathrm{Tsi})}{\sum_{\mathrm{i}=1}^{\mathrm{n}} \mathrm{Nb} \text { received packets }} * 1000(\mathrm{~ms})
$$

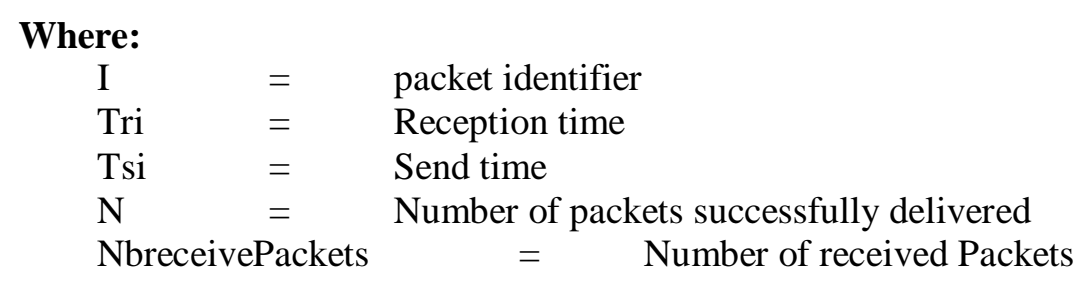

\subsection{Packet Loss Ratio}

Packet loss ratio is the number of packets that never reached the destination to the number of packets originated by the source $[3,13]$. We aim to decrease the packet loss ratio. The packet loss ratio is given as:

$$
P L R=\frac{\sum_{i=1}^{n} \text { nSentPackets-nReceivedPackets }}{\sum_{i=1}^{n} \text { nsentPackets }} * 100
$$

Where

$$
\begin{array}{lll}
\text { nSentPackets } & = & \text { Number of sent packets } \\
\text { nReceivedPackets }= & \text { Number of received packets }
\end{array}
$$

\section{Simulation ReSUlts}

In this section, the performance analysis is carried out on DSDV as proactive candidate and AODV as reactive representative, for different scenarios of high density of nodes and mobility. Last, a new distance vector hybrid proposal, ZRP is presented and compared with its predecessors. Performance metrics like Throughput, Packet Delivery Ratio, Dropped Packet, End to End Delay are the four common measures used for the comparison of the performance of above protocols. In the first scenario, the density of nodes varies from 10 to 100 nodes. We created a second scenario by changing the average speed within a margin of $10 \mathrm{~m} / \mathrm{s}$ to $90 \mathrm{~m} / \mathrm{s}$. The node mobility model is set up as Random Waypoint Mobility because it models the random movement of wireless sensor nodes. In order to enable direct fair comparisons between the protocols, it was critical to challenge the protocols with identical loads and environmental conditions. Each run of the simulator accepts an input scenario file which describes the exact motion of each node. Since the three chosen protocols were challenged with the same scenario file and during the same time (500 seconds), we can directly compare the performance results of 
all protocols carried out. Simulations were performed by using Network simulator 2 (NS 2.35) tool. It runs under LINUX operating system. We have used Tool Command Language (TCL) for implementation of routing protocols. Performance metrics are calculated from trace file, with the help of AWK program and it is plotted with the help of Microsoft Excel 2007 tool. The analysis result helps the network designer to choose right protocol. Simulation results are shown in the following section in form of line graphs.

\subsection{Scenario 1}

In this scenario, number of nodes connected in a network at a time is varied and thus varying the number of connections, through which the comparison graphs of AODV, DSDV and ZRP protocols, is made. All nodes are fixed at one place. Table 3 shows the main characteristics used for scenario 1 .

Table 3: Various parameters for scenario 1

\begin{tabular}{|l|l|}
\hline \multicolumn{1}{|c|}{ Parameter } & \multicolumn{1}{c|}{ Value } \\
\hline Routing Protocols & AODV, DSDV and ZRP \\
\hline Number of nodes & $10,25,50,75$ and100 \\
\hline Simulation Time & 500 seconds \\
\hline Traffic Type/Network Protocol & CBR/UDP \\
\hline Bandwidth & $0.4 \mathrm{Mb}$ \\
\hline Packet size & 1500 bytes \\
\hline Mobility Model & Off: A Fixed Topology \\
\hline Radio Propagation Model & TwoRay Ground \\
\hline Channel Type & Wireless channel \\
\hline Queue files & Queue/Drop Tail/Prique \\
\hline Queue length & 50 \\
\hline Mac layer & 802.11 \\
\hline Antenna Type & Omni Antenna \\
\hline Topology size & $1200 \times 1200$ \\
\hline
\end{tabular}

Table 4, table 5 and table 6 give performances results of the three routing protocols, with varying the number of nodes from within a margin of 10 to 100 nodes. Network traffic type is chosen as CBR (Constant Bit Rate). The routing protocols are set as AODV, DSDV and ZRP to compare the simulation data. The performance metrics used for comparison are Average Throughput, Endto-End delay, Packet Loss Ratio, and Delivered Packet Ratio.

Table 4. DSDV Evaluation for scenario 1

\begin{tabular}{|c|c|c|c|c|c|}
\hline $\begin{array}{c}\text { Number of } \\
\text { Nodes }\end{array}$ & $\begin{array}{c}\text { Number of } \\
\text { Packet Loss }\end{array}$ & $\begin{array}{c}\text { Delivered } \\
\text { Packet Ratio }\end{array}$ & $\begin{array}{c}\text { Packet Loss } \\
\text { Ratio }\end{array}$ & $\begin{array}{c}\text { Average } \\
\text { throughput }\end{array}$ & $\begin{array}{c}\text { End to End } \\
\text { Delay }\end{array}$ \\
\hline 10 & 1456 & 90.78 & 9.22 & 144.45 & 309.51 \\
\hline 25 & 692 & 93.90 & 6.09 & 100.57 & 147.84 \\
\hline 50 & 988 & 91.55 & 8.44 & 104.53 & 231.83 \\
\hline 75 & 599 & 90.91 & 9.08 & 58 & 166.27 \\
\hline 100 & 461 & 91.27 & 8.73 & 46 & 171.47 \\
\hline
\end{tabular}


Table 5. AODV Evaluation for scenario 1

\begin{tabular}{|c|c|c|c|c|c|}
\hline $\begin{array}{c}\text { Number } \\
\text { of Nodes }\end{array}$ & $\begin{array}{c}\text { Number of } \\
\text { Packet Loss }\end{array}$ & $\begin{array}{c}\text { Delivered } \\
\text { Packet Ratio }\end{array}$ & $\begin{array}{c}\text { Packet Loss } \\
\text { Ratio }\end{array}$ & $\begin{array}{c}\text { Average } \\
\text { throughput }\end{array}$ & $\begin{array}{c}\text { End to End } \\
\text { Delay }\end{array}$ \\
\hline 10 & 4701 & 77.85 & 22.15 & 182.48 & 301.27 \\
\hline 25 & 1595 & 90.59 & 6.09 & 142.8 & 160.78 \\
\hline 50 & 1881 & 86.91 & 8.44 & 120.68 & 138.84 \\
\hline 75 & 1234 & 89.6 & 11.08 & 98.89 & 156.76 \\
\hline 100 & 1175 & 88.92 & 8.73 & 46 & 157.31 \\
\hline
\end{tabular}

Table 6. ZRP Evaluation for scenario 1

\begin{tabular}{|c|c|c|c|c|c|}
\hline $\begin{array}{c}\text { Number of } \\
\text { Nodes }\end{array}$ & $\begin{array}{c}\text { Number of } \\
\text { Packet Loss }\end{array}$ & $\begin{array}{c}\text { Delivered } \\
\text { Packet Ratio }\end{array}$ & $\begin{array}{c}\text { Packet Loss } \\
\text { Ratio }\end{array}$ & $\begin{array}{c}\text { Average } \\
\text { throughput }\end{array}$ & $\begin{array}{c}\text { End to End } \\
\text { Delay }\end{array}$ \\
\hline 10 & 206 & 97.2 & 2.79 & 67.88 & 382.69 \\
\hline 25 & 702 & 93.77 & 6.22 & 102.13 & 192.25 \\
\hline 50 & 532 & 93.36 & 6.64 & 72.98 & 210.69 \\
\hline 75 & 413 & 91.14 & 8.86 & 41.91 & 211.69 \\
\hline 100 & 178 & 87.53 & 12.47 & 12.48 & 251.64 \\
\hline
\end{tabular}

All results are analyzed and briefed in form of graphs given below. These graphs are found very helpful in statistical analysis of these routing protocols. The required graphs were saved as the bitmap image for statistical analysis. In this figure, we estimate the average throughput for all three routing protocols namely AODV, DSDV and ZRP.

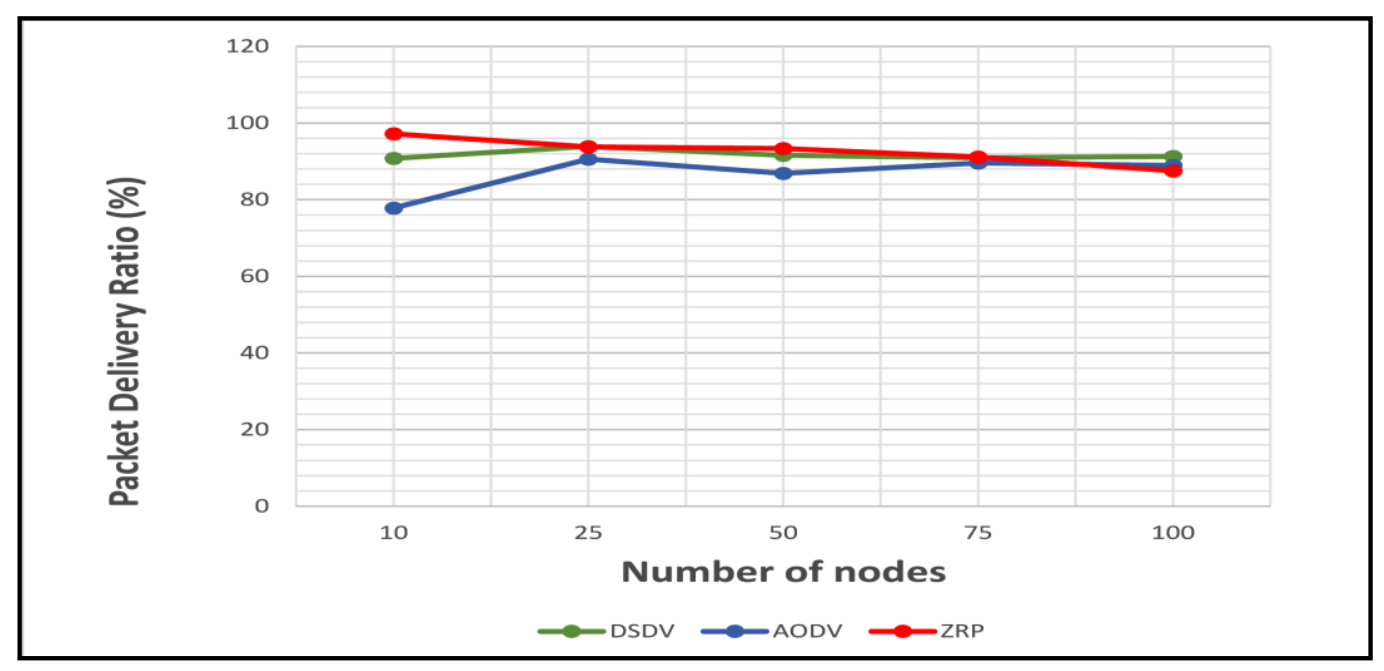

Figure 7. Packet Delivery Ratio for DSDV, AODV and ZRP

In Figure 7 we see the performance illustration of Packet Delivery Ratio depending on the number of nodes. DSDV and ZRP routing protocols are almost close to each other for varying number of nodes and we notice that the value of Packet Delivery Ratio remains constant and AODV shows variation. AODV performance dropped as number of nodes increase because more packets dropped due to link breaks. When we analyse where these lost packets are in AODV, we notice that AODV has not only more packets in buffers waiting for a route; but also, more 
packets are lost because they were sent following old routes. So AODV, suffers in part from its lack of periodic update information but maintaining reasonably good delivery ratio. In addition, ZRP improved the Packet Delivery Ratio since it finds new route to destination when link breaks existed. DSDV is slightly better than ZRP especially when the number of nodes is higher.

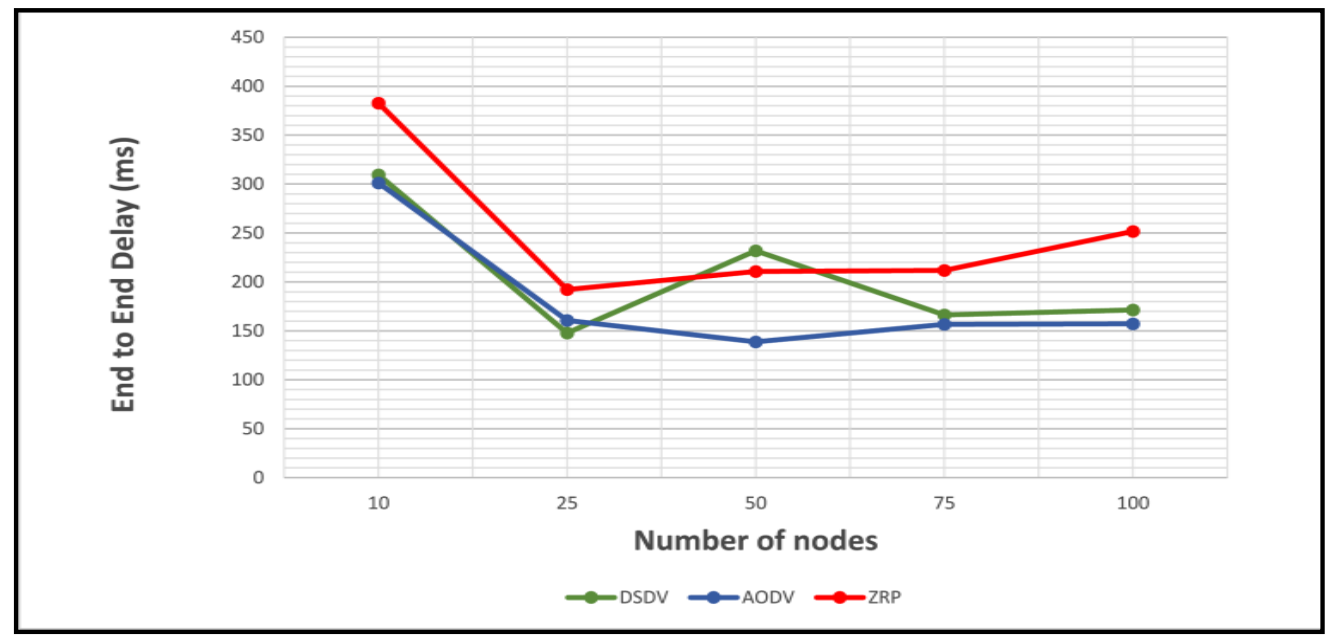

Figure 8. End to End Delay for DSDV, AODV and ZRP

This graph demonstrates the simulation results of End-to-End delay depending on the number of nodes. AODV didn't produce so much delay when the number of nodes increased. It performs better than the other two protocols. In addition, it shows that, the AODV protocol improved the DSDV when the number of nodes is over 50. The End-to-End Delay of AODV is less because it has reduced routing overhead and queuing delay. However, DSDV presents considerably less End to End delay than ZRP except at network size 50. Again, this shows that for delay-sensitive applications, DSDV protocol with a reduced density of nodes is remarkably well suitable. This attribute can be explained by the fact that DSDV is a proactive routing protocol and in these types of protocols the path to a destination is immediately available. Furthermore, DSDV routing protocol tries to drop the packets, if it is not possible to deliver them which means less delay. ZRP has higher delay than both DSDV and AODV routing protocols.

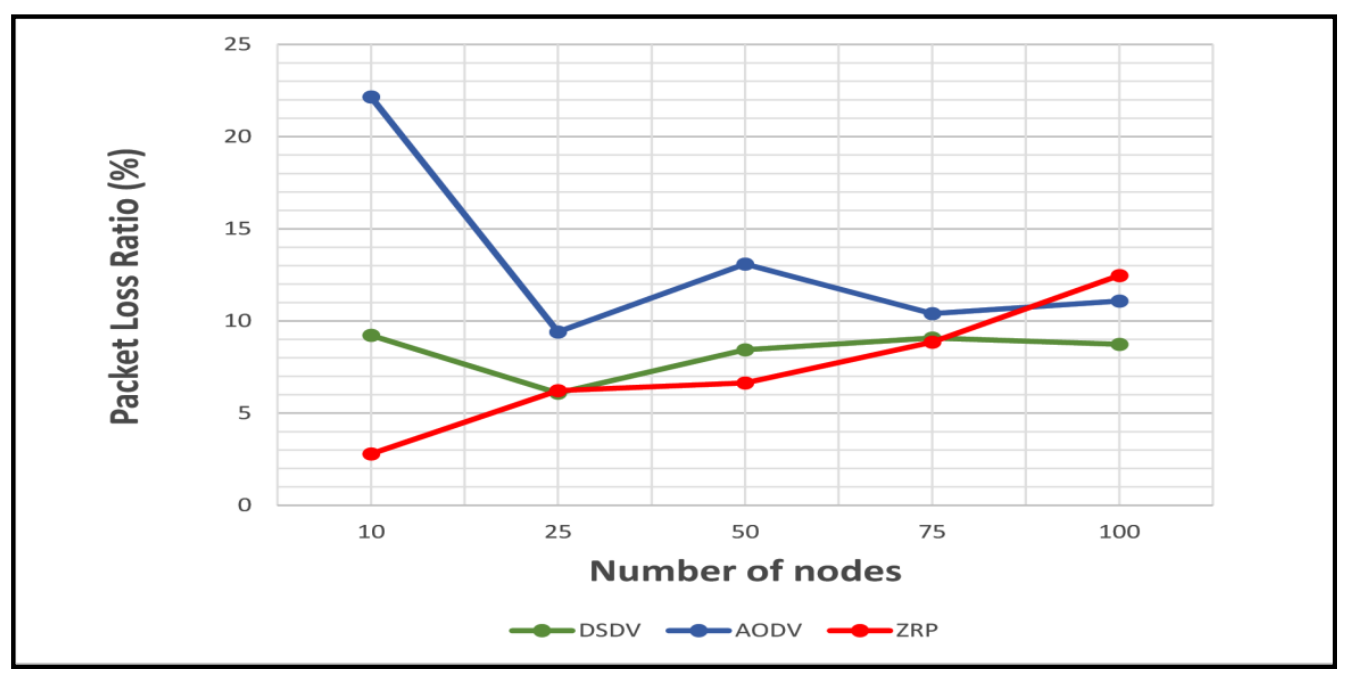

Figure 9. Packet Loss Ratio for DSDV, AODV and ZRP 
With increasing number of sensor nodes AODV shows worst performance. AODV seems to be more sensitive to the effect of the density of nodes. Once more AODV suffers from not always up-to-date information. For all smaller number of sensor nodes, performance of ZRP is better than AODV and DSDV, but for 100 sensor nodes ZRP shows maximum packet loss ratio. For DSDV protocol, the Packet Loss Ratio is not so affected as generated in ZRP. Since proactive routing maintains information that is immediately available, the Packet Loss Ratio before sending a packet is minimal in cost. So, overall, we can say that DSDV is the most preferred routing protocol for larger networks.

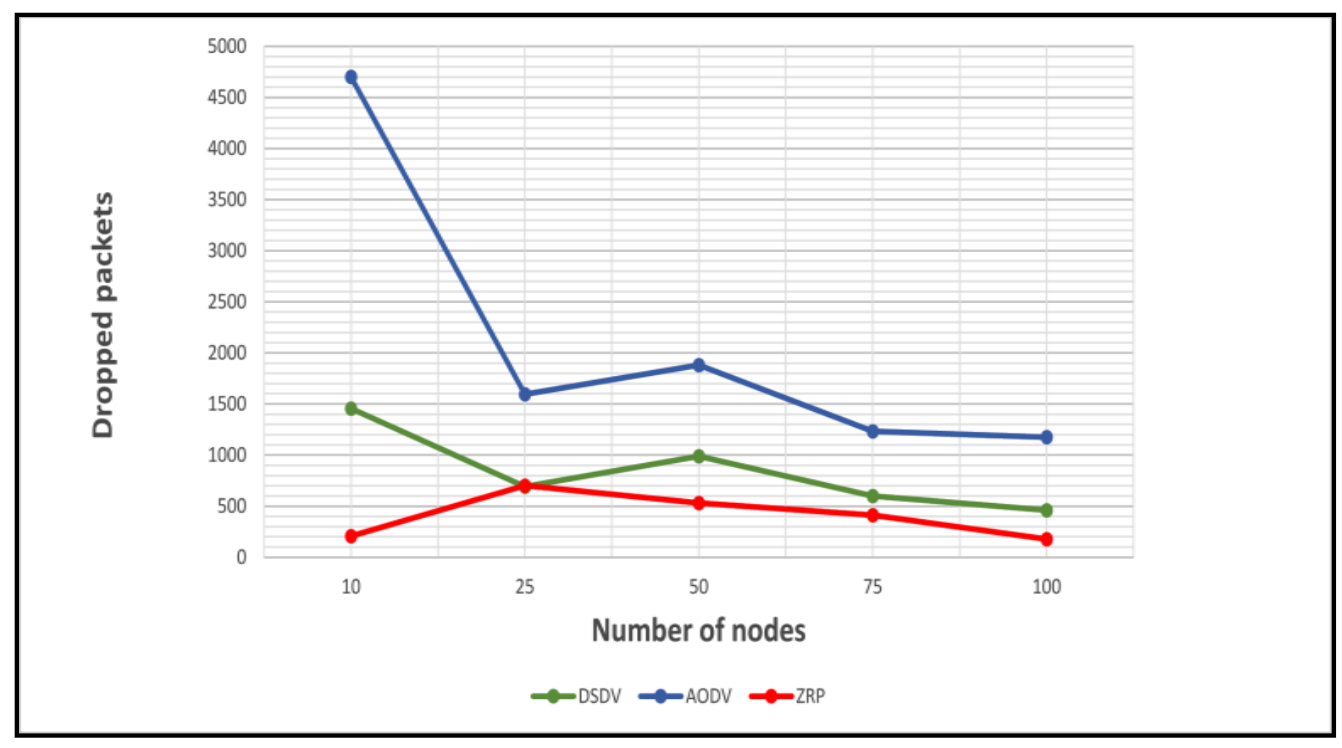

Figure 10. Dropped Packets for DSDV, AODV and ZRP

Here, we notice that as the number of nodes increases, the End-to-End delay becomes very high and increases with AODV. In case of ZRP, these parameters decrease as the density of nodes increases except when nodes are 25. This behaviour of ZRP is due to its hybrid nature because for smaller number of nodes, it behaves as a proactive routing protocol but for larger networks, it distributes the nodes into different zones and hence, due to IERP effect, it behaves as a reactive routing protocol. So overall, we can say that AODV is the most preferred routing protocol for larger networks in terms of End to End delay because its these parameters decrease more sharply than DSDV. Again, we conclude that with increasing number of sensor nodes AODV shows worst-performance. For 50 nodes AODV shows maximum dropped packet loss. Therefore, comparing to AODV and DSDV, ZRP presents the best results in terms of Dropped Packets.

\subsection{Scenario 2}

To see the effect of the mobility, the number of nodes is kept as 100 and speed of nodes is varying within a margin of $10 \mathrm{~m} / \mathrm{s}$ to $90 \mathrm{~m} / \mathrm{s}$. In the Architecture mode of the simulator the scenario is designed in an area of $1200 \mathrm{~m} \mathrm{x} 1200 \mathrm{~m}$. The routing protocols are set as AODV, DSDV and ZRP to compare the simulation data. 
Table 7. Various Parameters for scenario 2

\begin{tabular}{|l|l|}
\hline Parameter & Value \\
\hline Routing Protocols & AODV, DSDV and ZRP \\
\hline Number of nodes & 100 \\
\hline Simulation Time & 500 seconds \\
\hline Traffic Type/Application & CBR/FTP \\
\hline Bandwidth & $0.4 \mathrm{Mb}$ \\
\hline Packet size & 1500 bytes \\
\hline Mobility Model & Random Waypoint \\
\hline Speed of nodes & $10 \mathrm{~m} / \mathrm{s}, 30 \mathrm{~m} / \mathrm{s}, 50 \mathrm{~m} / \mathrm{s}, 70 \mathrm{~m} / \mathrm{s}$ and $90 \mathrm{~m} / \mathrm{s}$ \\
\hline Radio Propagation Model & TwoRay Ground \\
\hline Channel Type & Wireless channel \\
\hline Queue files & Queue/Drop Tail/Prique \\
\hline Queue length & 50 \\
\hline Mac layer & IEEE 802.11 \\
\hline Antenna Type & Omni Antenna \\
\hline Topology size & $1200 \times 1200 \mathrm{~m}$ \\
\hline
\end{tabular}

For scenario 2, table 8, table 9 and table 10 illustrate performance of AODV, DSDV and ZRP routing protocols, with varying speed of nodes within a margin of $10 \mathrm{~m} / \mathrm{s}$ to $90 \mathrm{~m} / \mathrm{s}$.

Table 8. DSDV Evaluation for scenario 2

\begin{tabular}{|c|c|c|c|c|c|}
\hline $\begin{array}{c}\text { Speed of } \\
\text { Nodes }\end{array}$ & $\begin{array}{c}\text { Number of } \\
\text { Packet Loss }\end{array}$ & $\begin{array}{c}\text { Delivered } \\
\text { Packet Ratio }\end{array}$ & $\begin{array}{c}\text { Packet Loss } \\
\text { Ratio }\end{array}$ & $\begin{array}{c}\text { Average } \\
\text { throughput }\end{array}$ & $\begin{array}{c}\text { End to End } \\
\text { Delay }\end{array}$ \\
\hline 10 & 218 & 90.5 & 9.5 & 20.14 & 159.58 \\
\hline 30 & 502 & 89.84 & 10.16 & 42.81 & 223.37 \\
\hline 50 & 407 & 92.04 & 7.96 & 44.7 & 131.64 \\
\hline 70 & 466 & 90.34 & 9.65 & 42.17 & 196.07 \\
\hline 90 & 527 & 89.63 & 10.37 & 44.3 & 175.1 \\
\hline
\end{tabular}

Table 9. AODV Evaluation for scenario 2

\begin{tabular}{|c|c|c|c|c|c|}
\hline $\begin{array}{c}\text { Speed of } \\
\text { Nodes }\end{array}$ & $\begin{array}{c}\text { Number of } \\
\text { Packet Loss }\end{array}$ & $\begin{array}{c}\text { Delivered } \\
\text { Packet Ratio }\end{array}$ & $\begin{array}{c}\text { Packet Loss } \\
\text { Ratio }\end{array}$ & $\begin{array}{c}\text { Average } \\
\text { throughput }\end{array}$ & $\begin{array}{c}\text { End to } \\
\text { End Delay }\end{array}$ \\
\hline 10 & 1184 & 88.85 & 11.2 & 88.25 & 157.14 \\
\hline 30 & 1195 & 88.42 & 11.58 & 68.1 & 181.15 \\
\hline 50 & 1276 & 88.44 & 11.56 & 92.08 & 146.9 \\
\hline 70 & 1259 & 88.62 & 11.38 & 92.3 & 140.7 \\
\hline 90 & 1308 & 88.13 & 11.87 & 91.97 & 168.72 \\
\hline
\end{tabular}


Table 10. ZRP Evaluation for scenario 2

\begin{tabular}{|c|c|c|c|c|c|}
\hline $\begin{array}{c}\text { Speed of } \\
\text { Nodes }\end{array}$ & $\begin{array}{c}\text { Number of } \\
\text { Packet Loss }\end{array}$ & $\begin{array}{c}\text { Delivered } \\
\text { Packet Ratio }\end{array}$ & $\begin{array}{c}\text { Packet Loss } \\
\text { Ratio }\end{array}$ & $\begin{array}{c}\text { Average } \\
\text { throughput }\end{array}$ & $\begin{array}{c}\text { End to End } \\
\text { Delay }\end{array}$ \\
\hline 10 & 243 & 87.11 & 12.88 & 16.64 & 240.94 \\
\hline 30 & 91 & 84.73 & 6.09 & 5.3 & 235.07 \\
\hline 50 & 78 & 83.04 & 8.44 & 11.32 & 230.37 \\
\hline 70 & 166 & 86.23 & 13.76 & 10.57 & 312.42 \\
\hline 90 & 461 & 91.27 & 8.73 & 18.03 & 171.47 \\
\hline
\end{tabular}

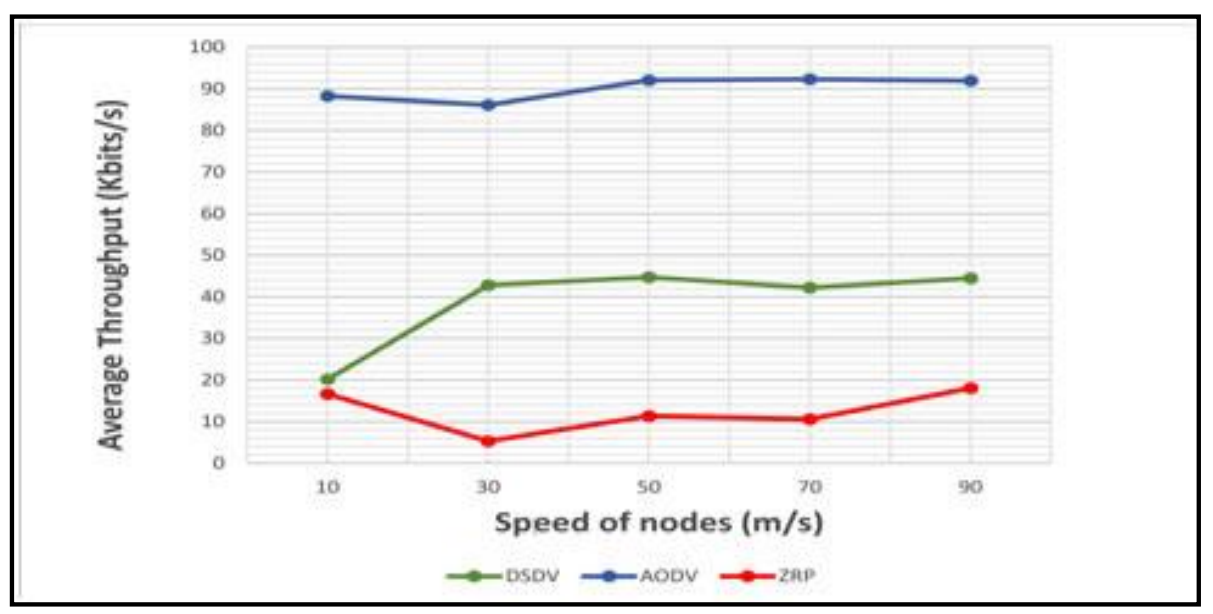

Figure 11. Average Throughput for DSDV, AODV and ZRP

The throughput is analysed with CBR (Constant Bit Rate) data traffic under the FTP (File Transfer Protocol) application. From this plotted result, we conclude that the average throughput in general increases steadily over the entire speed of nodes for all the routing protocols. ZRP outperforms the other two protocols but AODV attains the highest throughput and shows efficient behaviour in all mobility scenarios. Based on figure 11, it is shown that AODV attains the highest Average Throughput and shows efficient behaviour in all mobility scenarios. AODV produces more sent packet as it recovers from average throughput due to broken links in a higher node speed. ZRP performs a smaller number of packets delivered compared to the other two protocols.

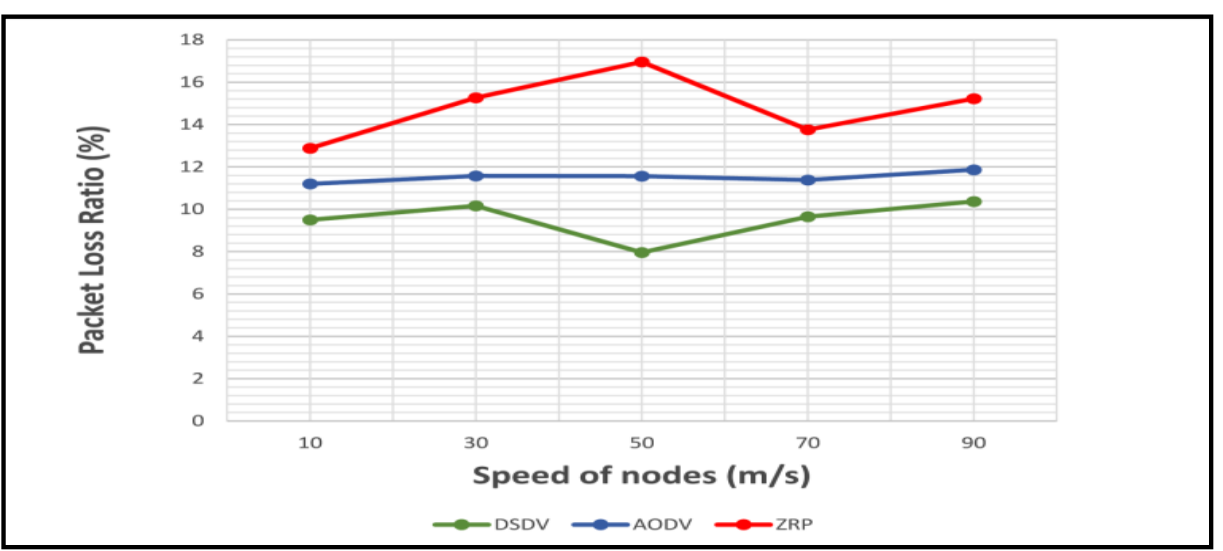

Figure 12. Packet Loss Ratio for DSDV, AODV and ZRP 
The result plotted for the three routing protocols AODV, DSDV and ZRP respectively for a second scenario having 100 nodes. AODV performs constantly when speed of nodes changes, whereas DSDV performs better than both AODV and ZRP in terms of packet loss ratio. Routes availability to all destinations implies that much less Packet Loss Ratio is involved in DSDV route setup process.

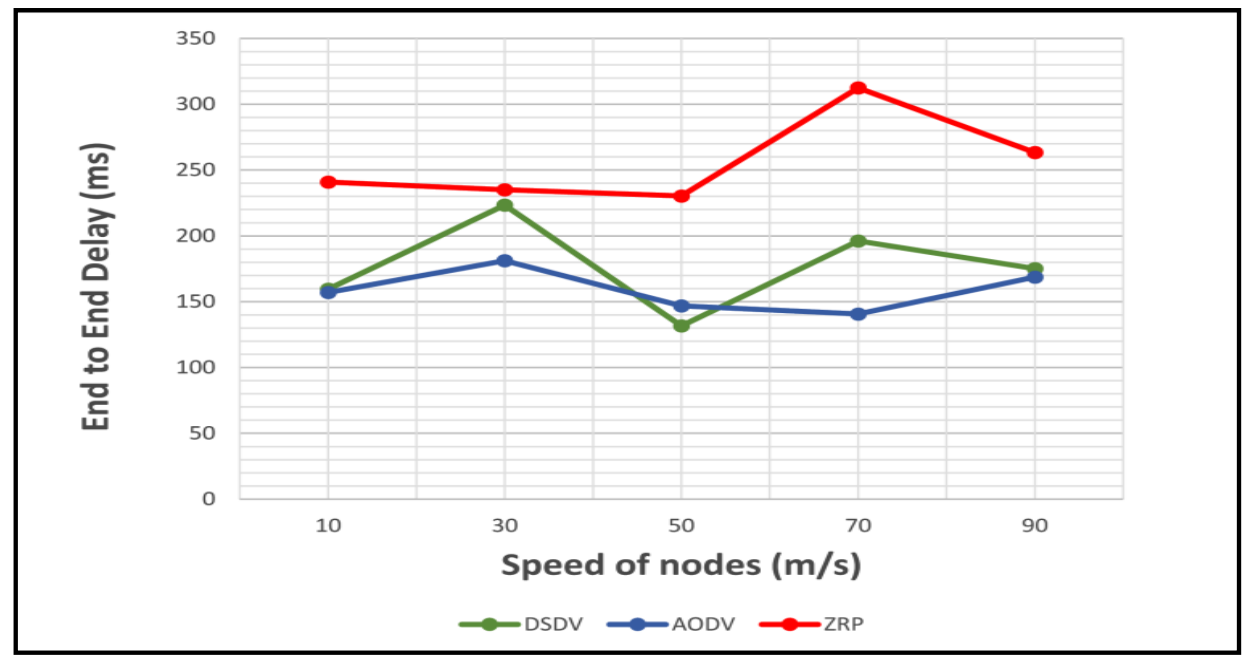

Figure 13. End to End Delay for DSDV, AODV and ZRP

These graphical results from figure 13 are measurement of end to end delay for the three routing protocols. AODV and DSDV perform better than ZRP in terms of End-to-End delay. When speed of nodes is $50 \mathrm{~m} / \mathrm{s}$, DSDV presents the better End-to-End delay than both AODV and ZRP protocols. Based on figure above, for varying speed, AODV produces less End to End Delay, but the performance of DSDV is slightly better than ZRP. ZRP renounce bad packet loss ratios or end to end delay values. It shows that for delay-sensitive application, AODV protocol with IEEE 802.11 standards performs efficient for wireless sensor networks. AODV routing protocol tries to drop the packets, if it is not possible to deliver them which, means less delay.

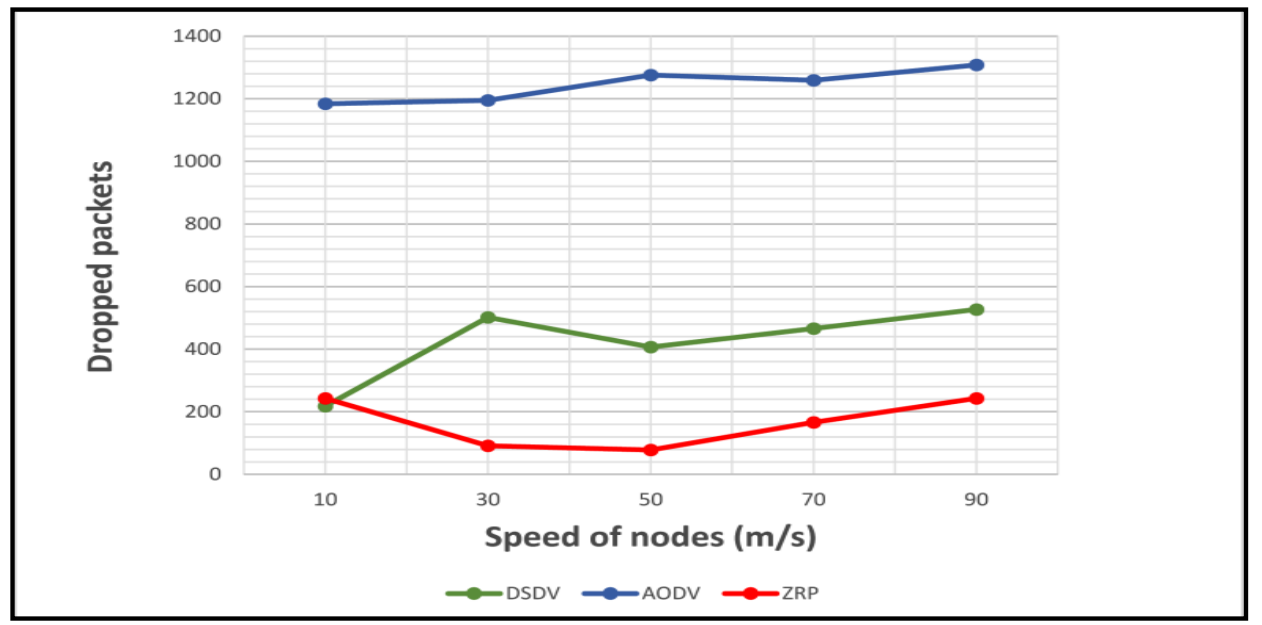

Figure 14. Dropped Packets for DSDV, AODV and ZRP 
Figure14 depicts the behaviour of the three proposed protocols in terms of dropped packets. Here we notice that as the speed of nodes increases, the value of mean Dropped Packets for AODV, DSDV and ZRP goes increasing. On the other hand, it is observed that ZRP protocol improves much better Dropped Packets in high mobility environments compared to AODV and DSDV protocols. So overall, we can say that ZRP is the most preferred routing protocol under high speed of nodes in terms of Dropped Packets. As resulting of that much dropped packets are occurred with AODV because the IEEE 802.11 protocol not enabled large packets transmission. On the other hand, reactive protocols must first determine the route, which may result in considerable dropped packets; moreover, the reactive route search procedure may involve significant control traffic due to the global flooding.

\section{LIMITATIONS OF NS 2 SIMULATOR}

NS-2 [27] is an object-oriented discrete event simulator targeted at networking research. The NS2 simulation environment offered great flexibility in studying the characteristics of WSNs because it includes flexible extensions for WSNs. NS-2 has a number of limitations: (1) It puts some restrictions on the customization of packet formats, energy models, MAC protocols, and the sensing hardware models, which limits its flexibility [27]. (2), the lack of an application model makes it ineffective in environments that require interaction between applications and the network protocols. (3) It does not run real hardware code. (4) It has been built by many developers and contains several inherent known and unknown bugs. (5) The performance of NS-2 is good for 100 nodes, which decreases significantly as the number of nodes increase. It does not scale well for WSNs due to its object-oriented design. (6) Using C++ code and OTCL scripts makes it difficult to use.

To overcome the above drawbacks the improved NS-3 simulator [27] was developed. NS-3 supports simulation and emulation. It is totally written in $\mathrm{C}++$, while users can use python scripts to define simulations. Hence, transferring NS-2 implementation to NS-3 require manual intervention. Besides the scalability and performance improvements, simulation nodes have the ability to support multiple radio interfaces and multiple channels. Furthermore, NS-3 supports a real-time schedule that makes it possible to interact with a real system [27]. For example, a real network device can emit and receive NS-3 generated packets.

\section{FUTURE RESEARCH DIRECTIONS}

In wireless sensor networks, routing is a challenge due to various characteristics that distinguish them from existing communication and wireless ad-hoc networks. New techniques of Hierarchical routing are a hot topic in this field for research. Due to the time limitations, our focus was only on some of the routing protocols during our study. DSDV was one of the early algorithms available. It is quite suitable for creating ad hoc networks with small number of nodes [20]. Since no formal specification of this algorithm is present. There is no commercial implementation of this algorithm [20]. Many improved forms of this algorithm have been suggested. Though, there are many other routing protocols that are needed to be analyzed. There are different design issues in WSN, like energy, heterogeneity, localization and synchronization which need to be explored further. Also, protocols security should be investigated with respect to various natures of attacks to which wireless communication is considered as an attractive target average throughput than DSDV and ZRP. Furthermore, performance comparison with other routing protocols in different classes could be done. In future, a mixture of two or more protocols can be used to give rise to a new type of WSN network satisfying more and more criteria. New techniques of Hierarchical routing are a hot topic in this field for research. 


\section{CONCLUSION}

In this study various routing protocols, namely AODV, DSDV, ZRP and various parameters like Average Throughput, End-to-End delay, Packet Delivery Ratio, Packet Loss Ratio and Dropped Packets have been discussed. We have considered two wireless sensor network scenarios, the first is by varying the number of nodes and the second is by varying the speed of nodes. AODV shows best performance in all mobility scenarios, with its ability to maintain connection by periodic exchange of information required for TCP network. By comparing the data collected from the three routing protocols, we analysed and proved that AODV is a more reliable protocol in terms of Delay and Average Throughput than DSDV and ZRP protocols. Network size has no considerable effect on AODV performance with respect to throughput but it does affect ZRP. The results can vary according to the metrics parameters. For some scenarios, Routing protocol DSDV has also performed good even than AODV is more reliable protocol in terms of End-toEnd delay and Throughput. At higher node mobility, AODV is worst in case of Packet Loss and Dropped Packets but it performs best for Packet Delivery Ratio. DSDV performs better than AODV for higher node mobility, in case of Packet Delivery Ratio and Packet Loss Ratio but ZRP performs best in case of dropped packets. However, not all of these protocols are efficient enough to fulfil all desired features of WSNs applications. From the conducted study on selected protocols, we have proved that there is no a best solution for a general mobile ad hoc network. The performance of one protocol may be far better in terms of delay other may be superior in terms of throughput. Secondly, network size also influences for protocols performance. Therefore, choice for selecting particular routing protocol will depend on application type and intended use of wireless sensor network. Finally, from the above research work performance of AODV is considered best for real-time and TCP applications. Therefore, the most successful applications of WSN technology will be those oriented to applications including large number of nodes. As we could see in section 6, each routing technique has specific advantages and disadvantages that make it suitable for certain types of scenario. In sensor networks, routing is an emerging area of research and who are becoming an increasingly popular wireless networking concept lately. Consequently, more and more research, is being conducted to find optimal routing algorithms that would be able to accommodate for such networks.

\section{ACKNOWLEDGEMENTS}

The author would like to acknowledge the support of Hamza Weslati, a student at Military Academy of Tunisia.

\section{REFERENCES}

[1] Y. jahir, M. Atiqzzman, H. Refai, A. Paranjathi, P. G. Loprest, "Routing Protocols and architecture for disaster area Network : a survey", Ad-hoc Networks Journal Elsevier 82-2019, 1-14.

[2] Hema, H. Sehrawat, "Comparative Analysis of Various Routing Protocol in Wireless Sensor Networks", International Journal of Innovations of Advancement in Computer Science, Volume 6, Issue 7, July 2017.

[3] S. Lalar, A. Yadav, "Simulation and Comparative Analysis of AODV, DSDV, DSR and AOMDV routing Protocol in WSN", IJEE, Volume 9, Number 1, Jan-June 2017, pp 9-15.

[4] S. NakhshabHussain, H. Raza, U. Tayyab, A. Razzak, "Multicast Zone Routing Protocol in Wireless Ad-hoc ", International Journal of Comuter Science and Network Security, Volume 17, ${ }^{\circ} 5$, May 2017.

[5] P. Patel, K. Patel, "Review Paper on Energy Efficient Routing Protocols in Mobile ad-hoc Network ", International Journal of Advance Engineering and Research Development," Special Issue Sieicom2017, April 2017. 
[6] M. Z. Chawy, M. A. Al Sanabani, , "Application and performance Analysis of DSDV Routing Protocol in Ad-Hoc Wireless Sensor Network with Help of NS2 Knowldge”, Global Journal of Computer Science and Technology: ENetwork, WEB and Security,vol. 17 issue 1 Version 1.0, p373379, 2017.

[7] J. Daniel Mano, S. Sathappan "Comparaison of Wireless Routing Protocols in Sensor Network Using NS2 Tool", International Journal of Advanced Research in Basic Engineering Sciences and Technology (IJRABEST), U.K, vol 2,Special Issue 19, October 2016.

[8] S. Chauhan, "Performance Evaluating of Routing Protocols for MANET using NS2", International Journal of Computer Science and mobile Computing, Vol 4, Issue 9, pg 242-249, septembre 2015.

[9] P. Boora, S. Malik, "Performance Analysis of AODV, DSDV, and ZRP Routing Protocols in WSN using Qualnet", International Journal of Enhaced Research in Science Technology of Engineering, vol 4, Issue 6, June 2015.

[10] G. Gautam, B. Sen, "Design and Simulation of Wireless Sensor Network in NS2", International Journal of computer Applications, vol. 113, No 16, March 2015.

[11] G. Kaur , E. Bhardwaj, "A Review On Energy Efficient Routing Protocols in Wireless Sensor Network, Mobile Ad-Hoc Network", International Journal of Research in Computer Applications and Robotics, vol 3, Issue 5, p36-41, May 2015.

[12] A. Arya, J. Singh, “Comparative Study of AODV, DSDV and DSR Routing Protocols in Wireless Sensor Network Using NS-2 Simulator”, International Journal of Computer Science and Information Technologies (IJCSIT), Vol. 5(4) IJCA, pp. 9-13, 2014.

[13] Mrs.Viashali, D. Khairnar, Dr K. Kotecha,"Simulation-Based Performance Evaluation of Routing Protocols in Vehicular Ad-hoc Network", International Journal of Scientific Research Publications, Volume 3, Issue 10, October 2013.

[14] S. Singh, Dr N. Hemrajani,"Performance Evaluation of AODV Routinng Protocol in Wireless Sensor Networks with the Constraints of varying terrains areas by varying pause time", , Interntional Journal of Emerging Trends and Technology in Computer Science (IJEITCS), Volume 2, Issue 1, JannuryFebury 2013 .

[15] P. Goswamis, Dr A.D. Jadhav, "Evaluating the Performance of Routing Protocols in Wireless Sensor Network", International Journal of Computer Technology and ELECTRONICS Enginnring (IJCTEE), Volume 2, Issue 3, June 2012.

[16] A. S. El. Ashhab, "Performance Evaluation of AODV and DSDV Routing Protocol in Wireless sensor Network Environment", International Conference on Compter Networs and communication systems", Vol 35, Singopore 2012.

[17] P. Kansal, D. Kansal, A. Balodi, "Comparison of Various Routing Protocol in Wireless Sensor Network ”, International Journal of Computer Applications, Volume 5-No.11, August 2010.

[18] P. Goswamis, Dr A.D. Jadhav, "Evaluating the Performance of Routing Protocols in Wireless Sensor Network, Volume 2, Issue 3, June 2012, pp557-567.

[19] A. Aggarwal, S. Gandhi, N. Chaubey, "Performance Analysis of AODV, DSDV and DSR in MANETS", International Journal of Distributed and Parallel Systems (IJDPS), Vol 2, N6, Novembre 2011.

[20] A. Abderahman, Z. Zukarnain, "Performance Comparison of AODV, DSDV and I-DSDV routing Protocols in Mobile Ad-hoc Networks”, European Journal of Scientific Research, Vol 31, N4, 2009, PP566-576.

[21] B. N. Jagdale. P. Patil, P. Lohane, D. Javale, "Analysis and Comparison of Distance Vector, DSDV and AODV Protocol of Manet", International Journal of Distributed and Paralle Systems (IJDPS), Vol 3, n 2 , March 2012.

[22] D. Bandral, R. Aggarwal, "Analysis of AODV and DSDV Routing Protocols for improving Quality of Service in MANET", vol 9, n³2, August 2016.

[23] L. Naikl, L.R.U. khon, R. B. Misha, "Analysis of Performance Improving parameters of DSDV using NS3", International research Journal of Engineering and Technology (IRJET), vol 3, Issue 7, July 2016, pp 446-452.

[24] S. Goverdhan, A.choubay,"Comparative analysis and Implementation of DSDV and AODV Routing Protocol for MANET", International Journal of Computer Techniques, Volume 2, Issue 3, May-June 2015, PP 90-97.

[25] Harsimrankau, J. Singh,"Comparison of AODV and DSDV protocols with improvement of AODV", International Journal of advanced research in Computer Engeneering of Technology (IJARCET), Volume 6, Issue 7, July 2017, pp 976-980. 
[26] Seema Pahal, Kusum Dalal, "A Review Paper on Routing Protocols in Wireless Sensor Networks", International Journal of recent trends in engineering and research, ISSN (Online) 2455 1457, 2016.

[27] Abdelrahman Abuarqoub, Fayez Al-Fayez, Tariq Alsboui, Mohammad Hammoudeh, Andrew Nisbet, "Simulation Issues in Wireless Sensor Networks: A Survey", The Sixth International Conference on Sensor Technologies and Applications, 2012.

[28] Madhuri Pal* Kalyani Satone Bhawa Chilke, "Implementation DSDV routing protocol for wireless mobile ad-hoc network, using NS-2 simulator", International Journal of Engineering Research \& Technology (IJERT) Vol. 1 Issue 8, October - 2012 ISSN: 2278-0181.

[29] Resumen_siemens, "Design, Implementation and Evaluation of Distance Vector Routing Protocols in Ad Hoc Networks".

[30] T.Praveena1, Mr.S.Parthasarathi, Dr.K.Hariharan," Performance Analysis of Different Routing Protocol Using Wireless Sensor Network in NS3", ISSN (PRINT): 2393-8374, (ONLINE): 23940697, Volume-4, ISSUE-12, 2017.

[31] Seema Pahal, Kusum Dalal, "Performance Evaluation of Routing Protocols in WSN using QualNet 5.3", International Journal of Recent Trends in Engineering and Research-2016.

[32] Marwan Aziz Mohammed, "Performance Study of AODV and DSDV Routing Protocols for Mobile Ad Hoc Networks Based on Network Simulator NS2”, Sulaimani Journal for Engineering Sciences / Volume 2 - Number 2 - 2015.

[33] Snehal Goverdhan, Aakanksha Choubey, "Comparative Analysis and Implementation of DSDV and AODV Routing Protocol for MANET”, International Journal of Computer Techniques - Volume 2 Issue 3, May - June 2015.

\section{AUTHOR}

Faïza Tabbana is an assistant professor of Military Higher Education of Foundek Jedid, Nabeul Tunisia. She has over fifteen years experience in teaching wireless, cellular and fixed networks like GSM (Global System for Mobile Communication), UMTS (Universal Mobile Telecommunication Standard), LTE (Long Term Evolution), Wimax, Wifi (IEEE 802.11), Ad-hoc Networks, TCP/IP networks and LANs (Local Area Networks). Her main research intersets include wireless networks planning and protocols. She worked for five years as Senior Engineer in a Center for studies and research in Telecommunication. She has published 4 papers in International Conferences (IEEE) and another paper in International Journal of Computer networks and Wireless Communications (IJNCWC).

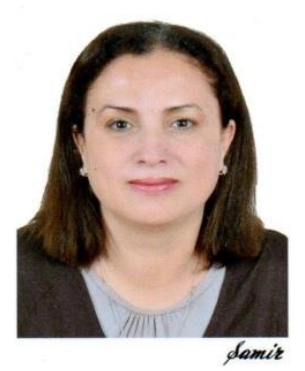

